\title{
Modelling Temperature Evolution in Equipment Engulfed in a Pool-fire
}

\author{
Eulàlia Planas-Cuchi \& Joaquim Casal \\ Centre d'Estudis de Risc Tecnològic (CERTEC), Department of Chemical Engineering, \\ Universitat Politècnica de Catalunya, Institut d'Estudis Catalans, Diagonal 647, \\ 08028-Barcelona, Catalonia, Spain
}

(Received 25 September 1996; revised version received 15 July 1997; accepted 1 August 1997)

\section{ABSTRACT}

$A$ method is presented to calculate the incident radiant heat flux and the temperatures reached on any point of a tank surface when this tank is engulfed in a pool-fire during the fire transitory state (developing phase). The method used to calculate the radiant heat flux on the cylinder is based on a three-dimensional formulation and uses the definition of a surface to establish the flame contour (according to a rectangular pool) taking into account the temperature changes with height and time.

The results are compared to experimental data obtained with large scale pool-fires of hexane and kerosene, and show a good agreement. Finally, some conclusions are derived. (C) 1998 Elsevier Science Ltd. All rights reserved.

Keywords: Fire; engulfment; modelling; flame; temperature

\section{NOTATION}

surface area, $\mathrm{m}^{2}$

$a$ $x$-coordinate of the point under consideration, $\mathrm{m}$

$g(y) \quad$ mathematical function giving the flame contour when $z>0$

$h \quad$ flame height, $\mathrm{m}$

$H \quad$ height of the combustion zone, $\mathrm{m}$

$h(y)$ mathematical function giving the flame contour when $z<0$ distance between the bottom of the cylinder and the ground, $m$

$h_{2} \quad$ distance between the top of the cylinder and the ground, $m$

$h_{3} \quad$ distance between the centre of the cylinder and the ground, $m$ $K$ mean absorption coefficient of the combustion gases, $\mathrm{m}^{-1}$ 
$L \quad$ cylinder length, $m$

$P \quad$ point of interest on the cylinder surface

$Q \quad$ radiative heat, $\mathrm{W} \cdot \mathrm{m}^{-2}$ distance between the centre of the cylinder and the point of interest, $\mathrm{m}$

$R \quad$ radius of the cylinder, $\mathrm{m}$

$S \quad$ absorbing path length, $m$

$t$ time, $\mathrm{s}$

$T_{\mathrm{f}} \quad$ flame temperature, $\mathrm{K}$

$V \quad$ volume, $\mathrm{m}^{3}$

$W \quad$ width of the pool-fire, $m$

$x$ horizontal coordinate, $\mathrm{m}$

$X \quad$ horizontal axis

$Y \quad$ vertical axis

$y \quad$ vertical coordinate, $\mathrm{m}$

$z \quad$ horizontal coordinate, $\mathrm{m}$

$Z \quad$ horizontal axis

$\phi \quad$ angle between the connecting vector and the vector normal to the surface element, rad (Fig. 2)

$\theta \quad$ angle between the vertical vector and the vector between the centre of the cylinder and the point of interest on the circumference of the cylinder, rad

$\sigma \quad$ Stefan-Boltzmann constant, $5 \cdot 66 \times 10^{-8} \mathrm{~W} \cdot \mathrm{m}^{-2} \cdot \mathrm{K}^{-4}$

\section{INTRODUCTION}

A recent historical analysis ${ }^{1}$ of accidents in the chemical industry and in the transportation of hazardous materials, carried out with a sample of 7029 entries corresponding to 6099 accidents which occurred during this century up to the end of 1993, has shown that the most frequent accidents involve fires $(41 \cdot 5 \%)$, followed by explosions (35\%) and gas clouds $(11 \cdot 2 \%)$. This implies a high frequency of fire accidents, which means that the contribution of fire to the risk of certain industrial installations and activities is very important. It should be taken into account that, although its direct effects cover a more reduced area than other accidents (for example, gas clouds), the action of fire on certain items of equipment can result in further escapes of hazardous substances and, thus, a much more serious incident.

The situation becomes very dangerous if the flames impinge on the surface of the process or storage equipment, and can be even worse if a piece of the equipment (for example, a reactor or tank) gets engulfed in the fire. This situation can be found in plants with a very compact lay-out such as some chemical process plants or off-shore oil platforms. 
To prevent such situations, a good knowledge of the phenomenon is required: the behaviour of the equipment engulfed in a fire must be modelled in order to be able to predict the evolution of temperature, the cooling rate required to keep the temperature in the safe range and, eventually, the time to bursting.

Several authors have studied the behaviour of equipment engulfed in fire. In a study published by Moodie ${ }^{2}$, one can find a brief review of the experimental work carried out between 1964 and 1986 by diverse authors and institutions. Few authors have done work on modelling. Birk and Oosthuizen ${ }^{3}$ have produced a two-dimensional analysis to estimate the radiant heat transfer to a horizontal cylinder engulfed in flames. Tunc et $a l^{4,5}$, and Wong and Stewart ${ }^{6}$ developed models for three-dimensional flame volumes. Finally, the model proposed by Beynon et al. ${ }^{7}$ gives a two-dimensional way to calculate the temperatures reached by a cylinder engulfed in flames.

We have not found any information in the literature concerning the behaviour of equipment engulfed in a pool-fire during the first stage, i.e. during the transitory state which corresponds to the growth and development of the pool-fire. Nevertheless, this first step - which usually lasts, approximately, $1 \mathrm{~min}$ - is very important because heat fluxes can reach very high values, originating in some cases very rapid failure of the equipment; for example, in the accident at San Juan Ixhuatepec (Mexico, 1984), after $69 \mathrm{~s}$ of flame impingement the first BLEVE's occurred. A good knowledge of this period is required if a fast control of the emergency is desired.

In this paper, a model is developed for the prediction of the behaviour of equipment engulfed in fire during this first - transitory - stage. The values predicted by the model are compared to experimental results ${ }^{8}$ obtained from pool-fires of hexane and kerosene of $4 \mathrm{~m}^{2}$ and $12 \mathrm{~m}^{2}$, respectively.

\section{INCIDENT RADIATION ON A CYLINDER ENGULFED IN A POOL-FIRE}

As stated before, the behaviour of equipment engulfed in a pool-fire has been treated by few authors. Tunc et al. ${ }^{4,5}$ proposed a three-dimensional formulation to determine the variation of incident radiant heat flux along the length and around the circumference of a tank engulfed in flames. The method used is very interesting, although some of the assumptions used by the authors made the results obtained unrealistic if one compares them with the experimental data obtained by other authors ${ }^{9}$. Tunc et $a l^{4,5}$ assumed a constant flame temperature over all the fire. Nevertheless, diverse experimental studies ${ }^{9,10}$ have proved that flame temperature varies with height; as the temperature is 
higher in the lower zone of the flame, the heat transfer rate in this zone is also more important.

In this article, the essential structure of the Tunc et al. method is used, although some of the assumptions used by these authors are changed - mainly those related to flame temperature variation - in an attempt to get closer to the real conditions.

The results derived from the proposed model are compared with the experimental data obtained in a set of large-scale tests conducted in the frame of an EC project ${ }^{8}$ and the experimental data obtained by other authors ${ }^{9,10}$.

In the present analysis, the following assumptions are made:

- The flames are considered as a grey body and so the flame emission is independent of the wavelength.

- The scattering of radiation is negligible.

- The flame absorption coefficient (or the extinction coefficient, which is the same as the scattering is considered to be negligible) is constant throughout the flame volume.

- The flame temperature is considered to be a function of time and height as described by Planas-Cuchi et al. ${ }^{11}$. This is an important point, as the flame temperature has a great influence on the model and, thus, on the results derived from it. The correlation used for the flame temperature is given by the following equation (which is slightly different from the one proposed in ref. 11 given that it has been improved):

$$
T_{\mathrm{f}}(t, h)=\frac{10^{4} \cdot t}{(34+210 \cdot h+8 \cdot 51 \cdot t)}+290
$$

- The effect of the convection heat transfer is considered to be negligible if compared with radiation heat transfer, especially in those cases in which the size of the equipment is large as compared to the size of the pool fire.

- The cylinder surface is considered as a black body.

\subsection{Flame shape}

In general, the classic treatment of flame shape supposes that the flame is like a cylinder which, in case of wind, may be tilted. Tunc et al. made a more realistic treatment, as they characterised the flame shape by means of axisymmetric flame contours obtained from photographs corresponding to large $(\phi \geq 4.5 \mathrm{~m}) \mathrm{JP}-4$ jet fuel pool-fires. In the work of Tunc et al., a fourth order polynomial is fitted to the contours of the flame to describe the radius of the flame as a function of height.

In the work presented here, the flame shape for a rectangular pool-fire $\left(4 \mathrm{~m}^{2}\right)$ is shown in Fig. 1. This contour has been derived from video recordings 


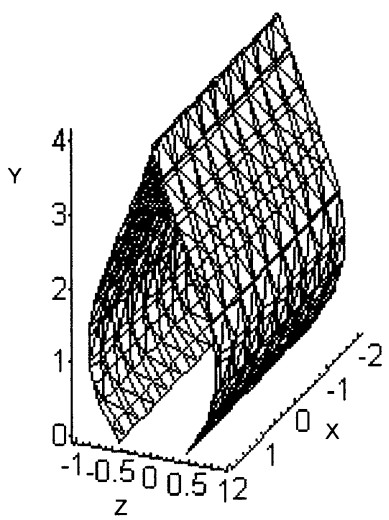

Fig. 1. Flame contour observed for a $4 \mathrm{~m}^{2}$ rectangular pool-fire (units in meters).

of experimental tests ${ }^{8,12}$. In this case, due to the geometrical pool characteristics - rectangular in shape - the flame cannot be approximated by a revolution surface or an axial symmetry surface which would represent a remarkable simplification. Thus, it has been necessary to use a more complex shape.

The analytic flame contour represented in Fig. 1 can be obtained from the following expressions:

$$
\left\langle\begin{array}{ll}
g(y)=0.449+0 \cdot 734 \cdot y-0.383 \cdot y^{2}+0.043 \cdot y^{3} & \forall z>0 \\
h(y)=-0.449-0.734 \cdot y+0.383 \cdot y^{2}-0.043 \cdot y^{3} & \forall z<0
\end{array}\right\rangle
$$

According to these equations, the flame width is a function of the flame height and is constant for each $y$ value.

Although during the first $60 \mathrm{~s}$ of the test the flame was in the transitory state and thus was growing, it was observed that this growth took place during the first $10 \mathrm{~s}$; after this period the flame dimensions remained approximately constant and the only parameter which changed was the temperature.

Obviously, the shape associated with the flame does not permit the flame changes caused by the wind induced by the fire itself to be taken into account. As can be observed from the experimental tests, these changes sometimes became significant. In this work it will be assumed that the flame shape is always totally symmetric.

\subsection{Radiation incident on the cylinder surface}

According to Fig. 2, the heat radiation exchange between the volume $V_{i}$ and the surface $A_{j}$ can be represented by:

$$
Q=\int_{V_{i}} \int_{A_{j}} \frac{K \cdot \sigma T_{\mathrm{f}}^{4} \cdot \cos \left(\phi_{i j}\right) \cdot \exp \left(-K \cdot S_{i j}\right)}{\left(S_{i j}\right)^{2}} \mathrm{~d} V_{i} \mathrm{~d} A_{j}
$$




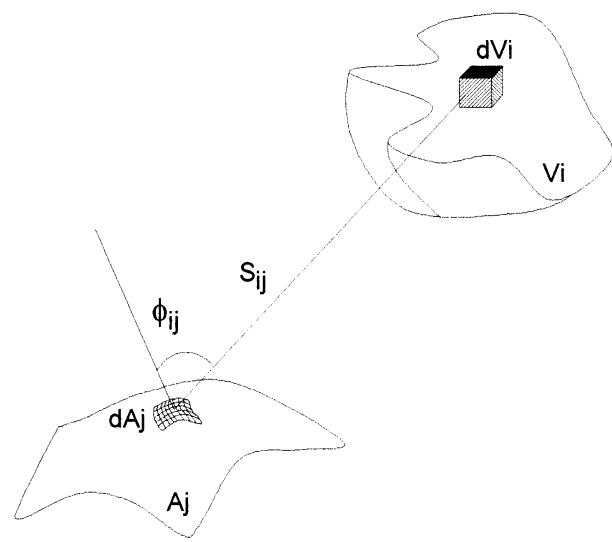

Fig. 2. Heat radiation exchange between a differential volume $\left(\mathrm{d} V_{i}\right)$ and a differential surface $\left(\mathrm{d} A_{j}\right)$.

In this expression, $K$ is the mean absorption coefficient; its value has been taken - for hexane-from the experimental data published by Atallah and $\operatorname{Allan}^{13}\left(K=1.9 \mathrm{~m}^{-1}\right)$. Thus, to determine the incident radiation on any point $P$ on the cylinder surface, $\cos \left(\phi_{i j}\right)$ and $S_{i j}$ must be previously defined. Then, the integration for all the gas volume that sees point $P$ has to be computed. Given the system geometry, this volume will depend on the position of point $P$ (Fig. 3).

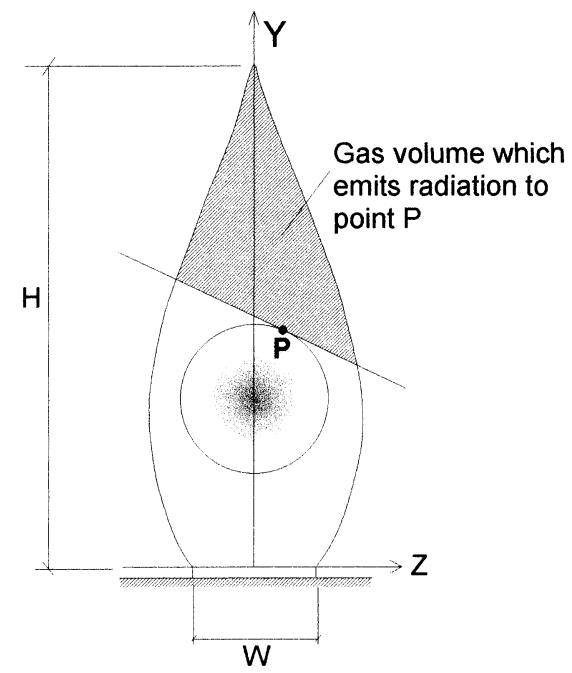

Fig. 3. Gas volume that emits radiation to a point $P$ on the cylinder surface. 


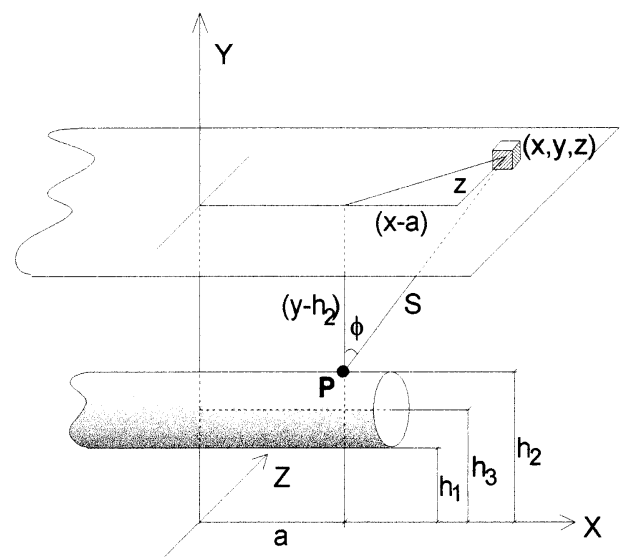

Fig. 4. Scheme showing the radiation incident on a point located along the length of the cylinder.

The radiation emitted by a point located in the flame volume, but outside the hatched volume in Fig. 3, will never reach point $P$ since it will be intercepted by another part of the cylinder surface and so should not be taken into consideration when computing the integration. Thus, the integration limits will be defined by the plane tangent to point $P$, the flame surface and the intersection between these two surfaces.

For a point placed along the length of the cylinder, Fig. 4 shows that $\cos (\phi)$ and $S$ take the following values:

$$
\begin{gathered}
\cos (\phi)=\frac{y-h_{3}-r}{S} \\
S^{2}=\left(y-h_{3}-r\right)^{2}+(x-a)^{2}+z^{2}
\end{gathered}
$$

For a point placed around the circumference of the cylinder (Fig. 5), the following expressions apply:

$$
\begin{gathered}
\cos (\phi)= \begin{cases}\frac{(z-r \cdot \sin (\theta))}{S \cdot \sin (\theta)} & \text { for } S \cdot \cos (\phi)>\overline{P b} \\
\frac{\left(h_{3}+r \cdot \cos (\theta)-y\right)}{S \cdot \cos (\theta)} & \text { for } S \cdot \cos (\phi) \leq \overline{P b}\end{cases} \\
S^{2}=\left(y-h_{3}-r \cdot \cos (\theta)\right)^{2}+(z-r \cdot \sin (\theta))^{2}+(x-a)^{2}
\end{gathered}
$$




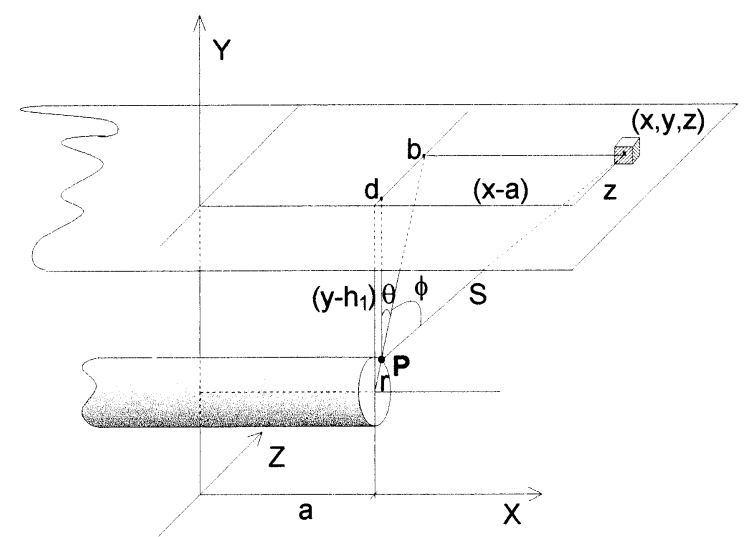

Fig. 5. Scheme showing the radiation incident on a point located around the circumference of the cylinder.

By substituting eqn (6) and (7) into eqn (3) and integrating over the adequate limits, the total radiation leaving the flame which is received by the cylinder surface can be calculated. The triple integral was solved numerically using a multidimensional Gaussian quadrature.

\subsection{Results}

The model developed in the previous paragraphs allows us to obtain the radiation reaching any point of the cylinder surface as a function of time (Fig. 6). As it can be seen, the bottom of the cylinder has a higher incident radiation (five-eight times higher) than the upper half of the cylinder. This can be attributed to two factors, the most important being the flame temperature, since this parameter increases when the height diminishes; another parameter which can contribute to this behaviour is the flame shape. The line corresponding to $\theta=180^{\circ}$ receives the maximum radiative heat flux $\left(90-100 \mathrm{~kW} \cdot \mathrm{m}^{-2}, 60 \mathrm{~s}\right.$ after ignition); this agrees fairly well with the experimental data which also show the maximum temperatures in this zone (during the experimental tests the vessel was totally empty). Other authors have found similar results ${ }^{9,10}$.

When comparing the radiation received by points located at the same height (i.e. same value of $\theta$ ), but at a different distance from the cylinder centre, a straight line is obtained. In this case, the reason can be found in the assumptions made to solve the problem: on one hand, as in the previous case, the flame shape which is constant in the $x$ direction; on the other hand, there is 


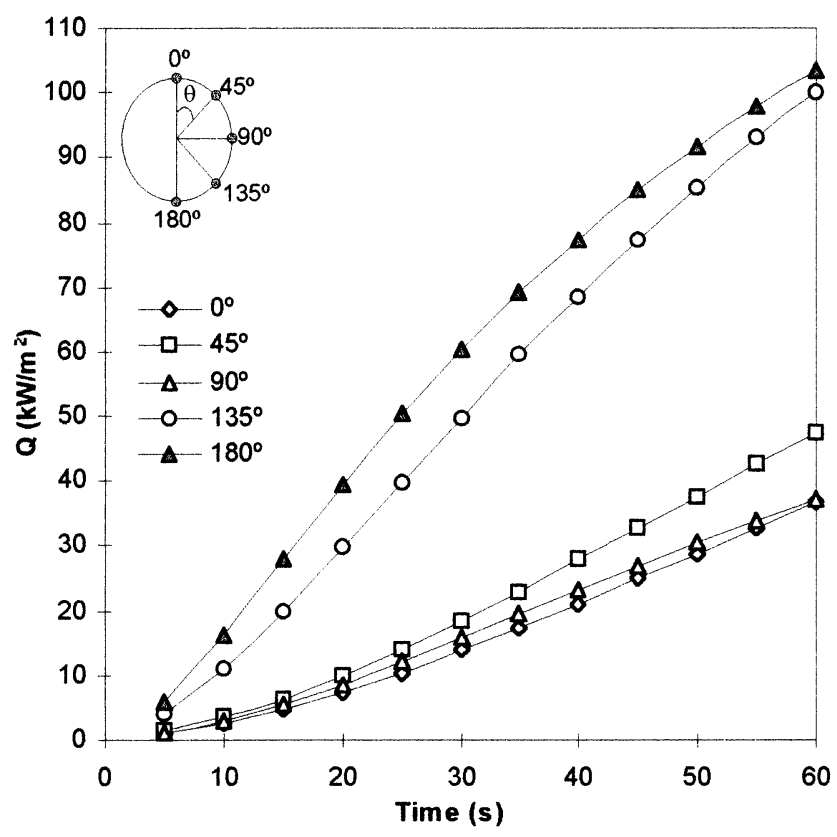

Fig. 6. Evolution of the incident radiant heat flux as a function of time. Points located at $a=1 \mathrm{~m}$.

also the flame temperature that has been assumed to be constant for all the points located at the same height.

Figure 7 shows the circumferential variation of the incident radiant heat flux. Between the angles 50 and $100^{\circ}$, the curve shows a minimum. This might seem strange, but if one observes Fig. 3 it can be seen that the points located between the angles 50 and $100^{\circ}$ have less flame volume at the right-hand side of the tangent plane to the point. Thus, although the flame temperature is higher than in the zone ranging between the angles of 0 and $50^{\circ}$, the global balance makes the radiation slightly lower.

In the case analysed here, one has to take into account the fact that the cylinder diameter $(1.2 \mathrm{~m})$ is higher than the pool fire width $(1 \mathrm{~m})$. This deforms the flame considerably in the zone occupied by the vessel. In the cases where the vessel is small compared to the flame size, the flame shape will have less influence when computing the incident radiant heat flux and, thus, the curve in Fig. 7 will probably have a different trend with a uniform shape.

This influence of the equipment engulfed in the fire on the fire itself can be important if the size of the equipment is relatively large compared to the size of the pool-fire. This hindering or obstructing effect has been quantified through a 'hindering factor' ${ }^{11}$ defined as the ratio between the heat released in 


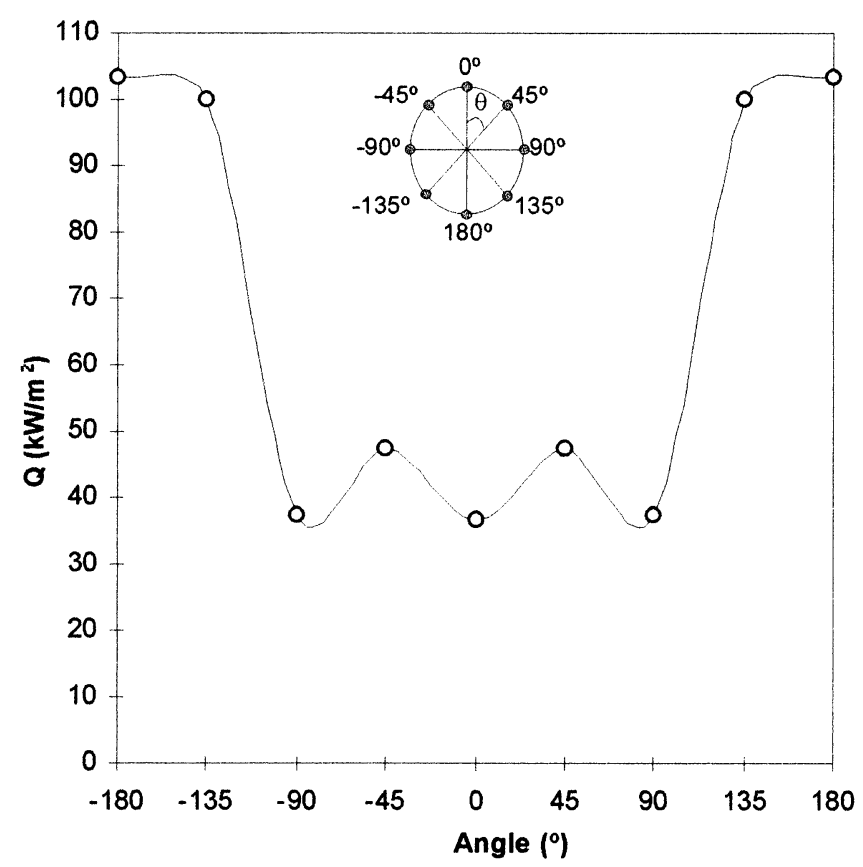

Fig. 7. Circumferential variation of the incident radiant heat flux. Points located at $a=1 \mathrm{~m}$, $60 \mathrm{~s}$ after ignition.

the combustion of a pool-fire with an obstacle (for example, a tank) and that released in the same pool fire with a free surface:

$\xi=\frac{\text { Heat released in the combustion of a pool with an obstacle }}{\text { Heat released in the combustion of the same pool without any obstacle }}$

This hindering effect has been proved to have an influence on the efficiency of the combustion and, finally, on the heat released by the pool-fire.

\section{TEMPERATURE OF THE CYLINDER SURFACE AS A FUNCTION OF TIME}

The knowledge of the radiation reaching the cylinder surface is interesting, although it becomes more understandable and easily comparable with the experimental data obtained from the thermocouples if it is translated directly to temperature. 
TABLE 1

Correspondence between nodes and thermocouples

\begin{tabular}{cc}
\hline Node & Thermocouple \\
\hline 0 & 20 \\
3 & 14 \\
5 & 8 \\
8 & 15,19 \\
10 & 9,13 \\
18 & 16,18 \\
20 & 4,6 \\
23 & 17 \\
25 & 11 \\
\hline
\end{tabular}

To find the evolution of temperature as a function of time on the diverse points of the cylinder surface, the method of finite elements has been used. The nodes distribution has been taken in such a way that all the measuring points in the experimental test have a corresponding node (Table 1 and Fig. 8). Although there are more nodes than measuring points (Fig. 9), this means more information and higher accuracy in the results obtained.

The cylindrical tank used in the experimental work was made of carbon steel, with a diameter of $1.2 \mathrm{~m}$, length $3 \mathrm{~m}$ and wall width $4 \mathrm{~mm}$. No surface

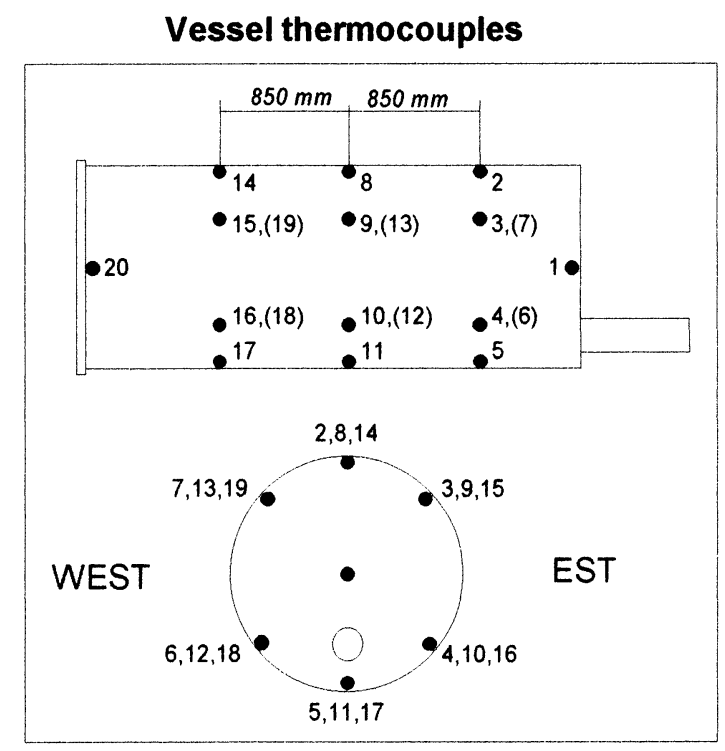

Fig. 8. Thermocouples distribution during the experimental tests. 

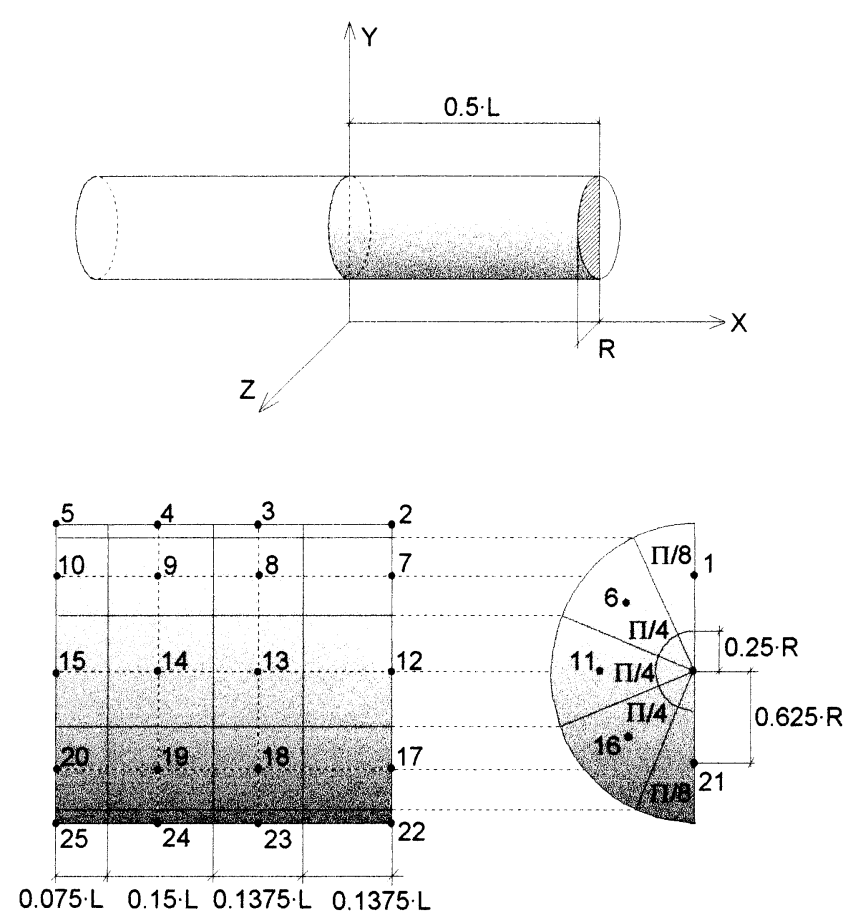

Fig. 9. Scheme showing the part of the cylinder used for the simulation. Nodes distribution in this part.

treatment had been applied to provide stable emissivity/absorptivity values and its inner surface was not insulated.

Due to the flame and the symmetry of the cylinder, the cylinder can be divided into four parts that ideally will have the same temperature distribution. Really, as can be observed experimentally, the system is not totally symmetric and the temperatures registered during the tests were not the same for points located symmetrically on the four parts of the cylinder (Fig. 9). Nevertheless, in order to simplify the modelling, it is necessary to suppose an ideal system, i.e. a totally symmetric one, and to take this into account when analysing the results obtained.

Thus, starting from time zero $(t=0)$ when the temperature in each node is considered to be equal to ambient temperature, the implicit method equation has been written for each node in the next time instant $(t=t+\Delta t)$. Then, a system of 26 equations with 26 unknowns is obtained, where every equation gives the temperature of one node as a function of the temperature of the nodes surrounding it in the same instant and also as a function of the temperature of the node itself in the previous instant. This system must be 

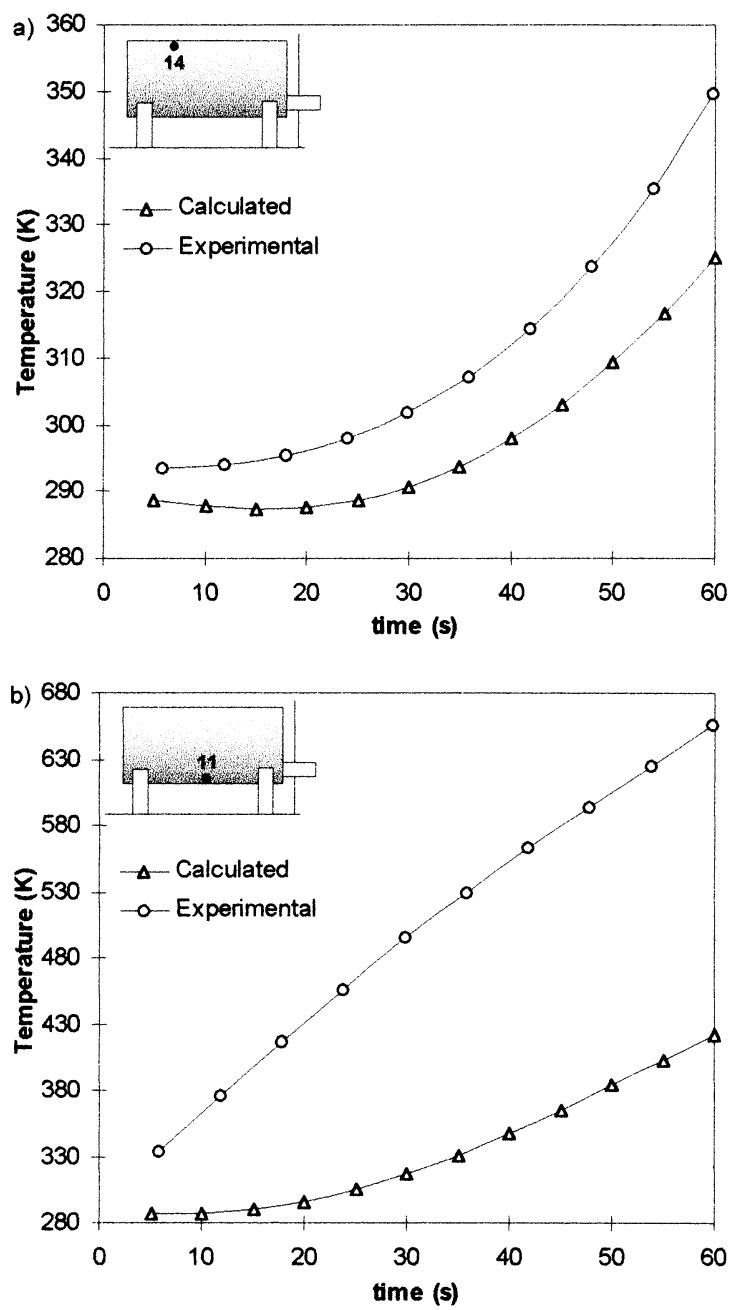

Fig. 10. Experimental and calculated temperature evolution with time. (a) Thermocouple 14. (b) Thermocouple 11 .

solved for every time increment. A C code applying a numerical method of triangular factorisation was used.

In general, the results obtained tend to underestimate the evolution of temperature with time on any point of the tank; this difference is more important on the lower part. Figure 10(a) shows that on the upper part of the vessel (thermocouple 14), the experimental temperatures are relatively similar (differences of $25 \mathrm{~K}$, the maximum temperature being $350 \mathrm{~K}$ ) to those obtained from the model. However, the temperatures recorded by thermocouple 11, located on the lower part of the vessel [Fig. 10(b)], are significantly higher 
than those obtained from the model; in this case, the differences are approximately $230 \mathrm{~K}$ (the maximum temperature being $650 \mathrm{~K}$ ). This means that between the lower and upper part of the vessel the error induced by the model is practically duplicated.

When analysing these results, it is important to take into account the fact that the most important parameter in the model is the flame temperature, since it determines the heat that the vessel will receive. Any error made when evaluating the flame temperature will directly affect the temperatures attained by the tank and, in addition, this error is increased because of the fourth power appearing in eqn (3). Thus, the relatively large discrepancy observed in Fig. 10(b) between the predicted values and the experimental results is due to an underestimation of flame temperature in the lower zone of the flame.

Figure 11 shows the temperatures reached $60 \mathrm{~s}$ after ignition, according to the model and the experimental tests, respectively; the thermocouples from both sides of the vessel are shown. As it was discussed previously, the model gives totally symmetric results since it does not take into account the wind induced by the flames or the fact that the system (experimental installation) is not totally symmetrical. From the experimental results it can be observed that two symmetrical thermocouples (for example, thermocouples 3 and 7) do not record the same temperature.

If the values reached by the model are compared to the experimental values, it can be observed that both sets of values (white and grey bars in Fig. 11) show practically the same trend with temperatures increasing from the upper to the lower part of the vessel and with temperatures from the front part of the vessel being slightly higher. Nevertheless, it must be noticed that some points have important differences (thermocouples 5,11,17), all of which correspond to points located on the lower part of the vessel.

As has been said before, the results derived from the model are directly related to the flame temperature selected. This temperature was calculated from an experimental correlation ${ }^{11}$ obtained from thermocouples data and corrected with radiometers data. The radiometers measured the radiation from the flame surface and so the temperature derived also corresponds to this part of the flame. Thermocouples 5,11 and 17 were located far from the flame surface, in a zone which can only be reached by fresh air with difficulty and where the combustion takes place with less air excess than in the flame boundary. Thus, the temperatures reached by the flame in this zone are probably higher than those estimated by the correlation. Notwithstanding, this is an effect that, for the moment, the model can not take into account using the available information. A more profound study would be needed on the evolution and distribution of temperatures around the flame volume in order to develop a better correlation for the flame temperature. 


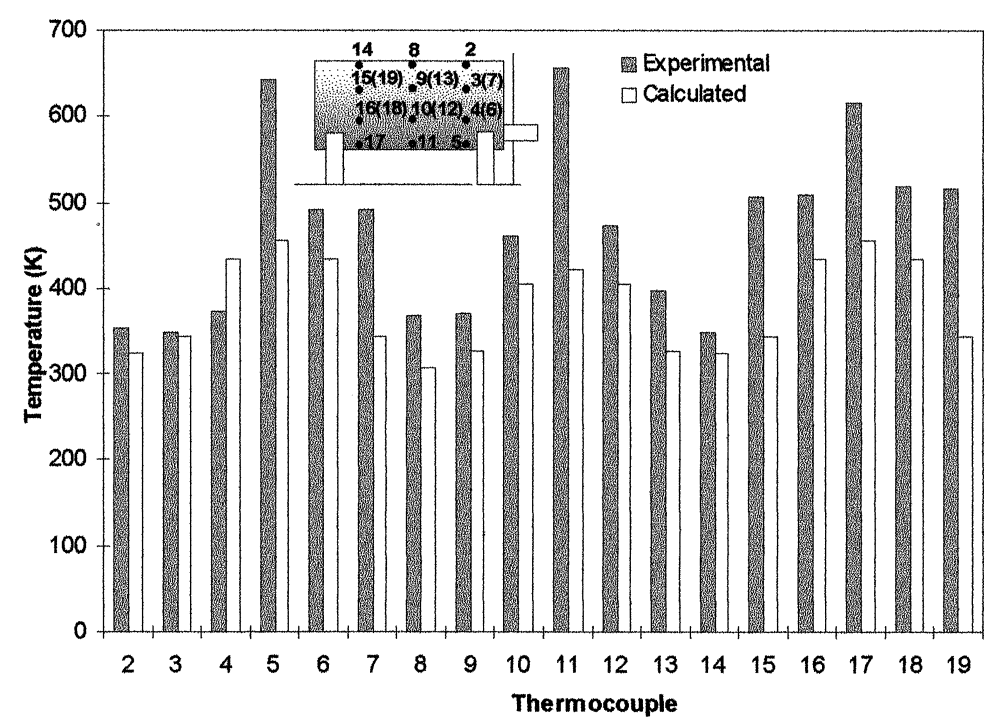

Fig. 11. Temperature reached by the thermocouples located on the vessel surface $(60 \mathrm{~s}$ after ignition). Experimental and calculated values. In the vessel scheme, the numbers in brackets correspond to thermocouples located on the west side of the vessel.

Another fact to be taken into account is that the underestimation of temperatures on the lower part of the vessel will have an effect on the other points of the vessel (due to longitudinal heat conduction) which will consequently reach lower temperatures.

In addition to these three thermocouples, there are three more which attract attention-7,15 and 19 - since in this case the model also underestimates the temperatures reached. The reason is not the same as in the previous case. Thermocouples 7,15 and 19 are on the half upper part of the vessel, on a point not far from the flame surface which is well ventilated and so it is likely that flame temperatures on these points are well estimated. Here it should be noted that thermocouples 9 and 13, located at the same height and at a distance less than $1 \mathrm{~m}$ from thermocouples 15 and 19, have lower temperatures (approx. $120 \mathrm{~K}$ lower); the case of thermocouples 3 and 7 is still more significant since both points are symmetrical and so they should show the same temperature. There may be two reasons for this: either the reading from these thermocouples was not correct (all the tests show the same trend) or in fact, and due to the effect of the induced wind, these points receive much more heat than the rest. Both assumptions are difficult to prove since there is not sufficient information available.

All the references found in the bibliography concerning the temperatures reached by tanks engulfed in flames deal only with experimental work or, if 


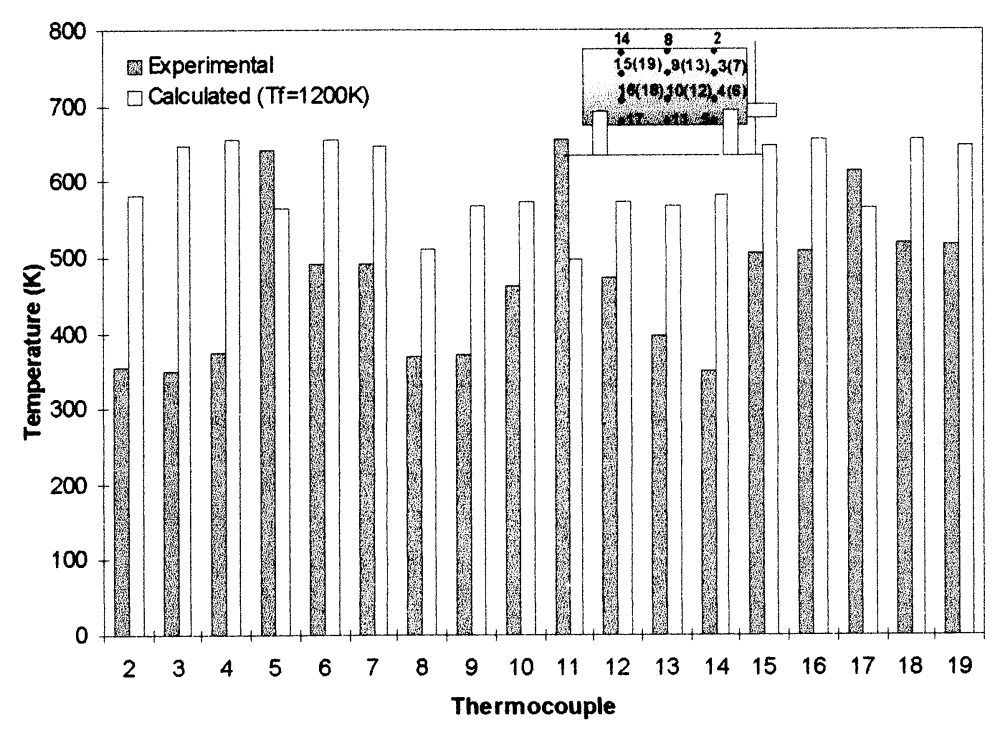

Fig. 12. Temperature reached by the thermocouples located on the vessel surface $(60 \mathrm{~s}$ after ignition). Experimental values and values calculated with the model taking a constant flame temperature equal to $1200 \mathrm{~K}$.

they develop a model, could be applied only to steady state taking a constant flame temperature.

Figure 12 shows the values reached by the model if a constant flame temperature of $1200 \mathrm{~K}$ is taken (this is the most frequent value taken by different authors for the flame temperature when constant and uniform). The significant differences with the experimental results can be observed, not only in the values reached, but also, and above all, in the temperature distribution between the diverse points.

According to the model, 1 min after ignition, the vessel will be practically at a uniform temperature of $600 \mathrm{~K}$, while the experimental values show that really this temperature varies a great deal from one point to another. This shows again that the simplifying assumption that flame temperature is constant is misleading and reduces the validity of these models.

\section{CONCLUSIONS}

A method to estimate the incident radiant heat flux on a cylinder engulfed in flames has been developed. This model takes into account the variation of flame temperature with height and time.

The model shows that flame temperature is one of the most influential parameters and that, as already suggested by other authors ${ }^{8,9,14}$, taking 
a constant value for the flame temperature can be a misleading assumption. Moreover, the flame shape and relative sizes of the flame and cylinder (or any object engulfed in the flames) have a significant influence. Although the circumferential incident radiant heat flux increases uniformly with decreasing height due to the variation of the flame temperature, in some cases (as in the example presented here) this is not exactly true because of the presence of the object (the tank) which deforms the flame and the combustion products to be cooled.

The model has also shown that once the radiative heat transfer has been determined, it is relatively easy to find the temperature distribution on the cylinder surface. This temperature is important because this parameter defines the operating limits of the material and, thus, allows the approximate time to bursting to be calculated.

Although the temperatures obtained with the model are somewhat lower than the experimental values, the trend in the temperature distribution on the cylinder surface is very similar. The proposed model, much closer to real conditions than the models previously published, is, therefore, a step forward in the modelisation of the behaviour of equipment engulfed in fire. Nevertheless, further work should still be done, especially to achieve a better correlation for the estimation of the flame temperature.

\section{ACKNOWLEDGEMENTS}

The authors acknowledge Dtt. A. Lancia and Ing. L. Bordignon from TRI for the experimental information supplied on the experimental data.

The authors also acknowledge the financial support from the Comissionat per Universitats i Recerca de la Generalitat de Catalunya (Project n. GRQ943009).

\section{REFERENCES}

1. Planas-Cuchi, E., Montiel, H. \& Casal, J., A survey of the origin, type and consequences of fire accidents in process plants and in the transportation of hazardous materials, Process Safety and Environmental Protection, Trans. IChem E, 75, 3-8.

2. Moodie, K., Experiments and modelling: An overview with particular reference to fire engulfment. Journal of Hazardous Materials, 20 (1988) 149-75.

3. Birk, A. M. \& Oosthuizen, P. H., Model for the prediction of radiant heat transfer to a horizontal cylinder engulfed in flames. ASME Paper 82-WA/HT-52, 1982.

4. Tunc, M. \& Venart, J. E. S., Incident radiation from an engulfing pool-fire to a horizontal cylinder. Fire Safety Journal, 8 (1984) 81-7.

5. Tunc, M. \& Karakas, A., Three-dimensional formulation of the radiant heat flux variation on a cylinder engulfed in flames. Journal of Heat Transfer-Transactions of the ASME, 107 (1985) 949-952. 
6. Wong, S. \& Steward, F. R., Radiative interchange factors between flames and tank car surfaces. Journal of Hazardous Materials, 20 (1988) 137-46.

7. Beynon, G. V., Cowley, L. T., Small, L. M. \& Williams, I., Fire engulfment of LPG tanks: HEATUP, a predictive model. Journal of Hazardous Materials, 20 (1988) 227-38.

8. Foam and water deluge systems for off-shore oil platforms, Project Summary Report, EC Contract: TH-15.125/89-IT.

9. Gregory, J. J., Keltner, N. R. \& Mata, R. Jr., Thermal measurements in large pool-fires. Journal of Heat Transfer-Transactions of the ASME, 111 (1989) 446-54.

10. Bainbridge, B. L. \& Keltner, N. R., Heat transfer to large objects in large pool-fires. Journal of Hazardous Materials, 20 (1988) 21-40.

11. Planas-Cuchi, E., Casal, J., Lancia, A. \& Bordignon, L., Protection of equipment engulfed in a pool-fire. J. Loss Prev. Process Ind., 9(3) (1996) 231-40.

12. Casal, J., Planas-Cuchi, E., Lancia, A. \& Bordignon, L., Fire Engineering and Emergency Planning. Research and Application, ed. R. Barham, Chapman and Hall, London, 1996, pp. 209-217.

13. Atallah, S. \& Allan, D. S., Safe separation distances from liquid fuel fires. Fire Technology, 7(1) (1971) 47-56.

14. Keltner, N. R., Nicolette, V. F., Brown, N. N. \& Bainbridge, B. L., Test unit effects on heat transfer in large fires. Journal of Hazardous Materials, 25 (1990) 33-47. 